\title{
Working
}

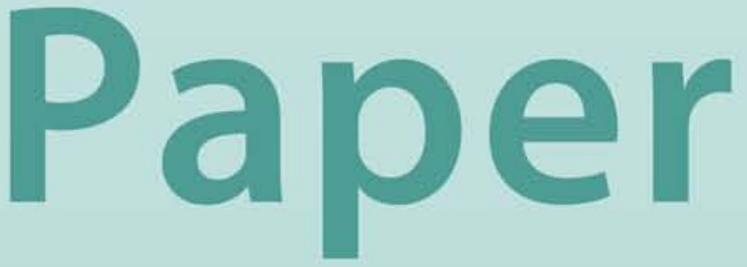




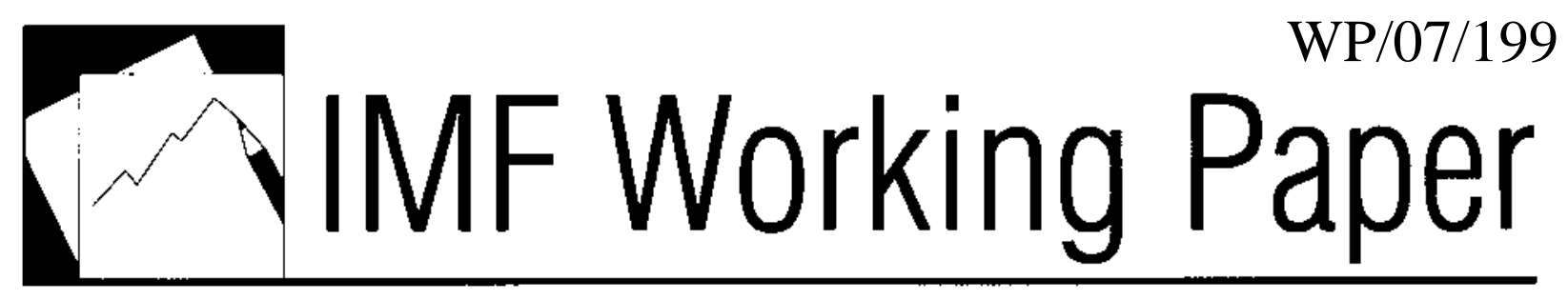

\section{The Golden Rule and the Economic Cycles}

Keiko Honjo 


\title{
IMF Working Paper
}

\author{
European Department
}

\section{The Golden Rule and the Economic Cycles}

Prepared by Keiko Honjo*

Authorized for distribution by James Morsink

August 2007

\section{Abstract}

\section{This Working Paper should not be reported as representing the views of the IMF.}

The views expressed in this Working Paper are those of the author(s) and do not necessarily represent those of the IMF or IMF policy. Working Papers describe research in progress by the author(s) and are published to elicit comments and to further debate.

The present formulation of the golden rule in the United Kingdom allows fiscal performance to be tested explicitly on an ex-post basis. However, it requires precise dating of the economic cycle, which can lead to significant controversy. Also, the need to aim for current balance or better "over the cycle" may force fiscal policy to be procyclical toward the end of cycles. Using dynamic stochastic simulations, the paper suggests that making the formulation of the golden rule forward-looking and independent of the dating of the economic cycle would reduce the risk of procyclicality and enhance macroeconomic stability.

JEL Classification Numbers:E12, E17, E32, E61, E62, H11, H68

Keywords: Golden rule, fiscal rule, procyclical fiscal policy, economic cycle, macroeconomic stability

Author’s E-Mail Address:khonjo@imf.org

\footnotetext{
* I am very grateful to Ben Hunt for helpful discussions, and Kexue Liu and Heesun Kiem for providing help with Troll codes. I also would like to thank Dennis Botman, James Morsink, and the seminar participants at the U.K. Treasury for comments and suggestions.
} 


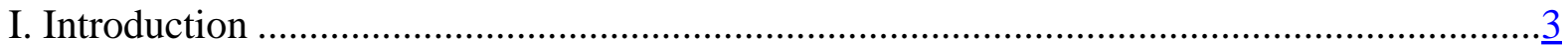

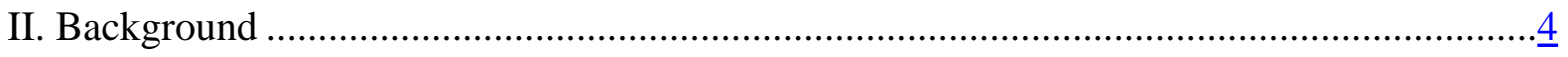

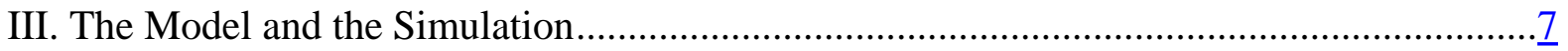

A. The Economic Cycle_-Definition and Identification .......................................... $\overline{9}$

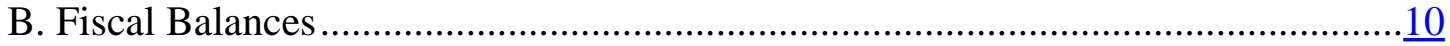

IV. Simulation Results .........................................................................................

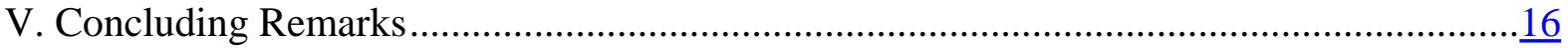

\section{Tables}

1. Golden Rule: Procyclical Fiscal Policy During the Cycle ...............................................13

2. Comparison of Economic Performance Over the Cycle..................................................14

3. Forward-Looking Rule with a Debt Band: Procyclical Fiscal Policy During the Cycle......15

4. Alternative Rule: Different Horizons.........................................................................16

\section{Figures}

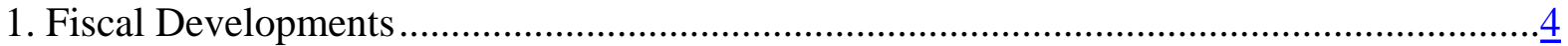

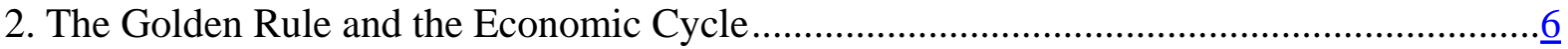

3. Sequence of Decisions in Each Period............................................................................ $\frac{8}{8}$

4. Economic Cycles ............................................................................................. $\frac{10}{12}$

5. Distribution of Cumulative Balance at the End of the Cycle..........................................12

\section{Appendixes}

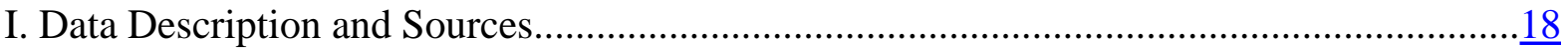

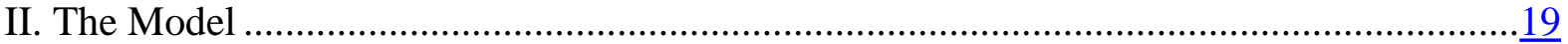

\section{Appendix Tables}

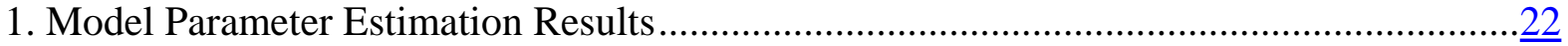

2. Estimation Results for the Error Processes and Measurements Errors...............................23

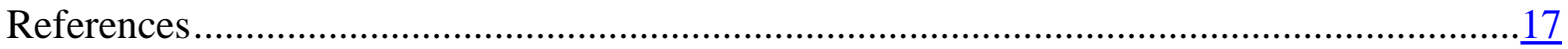




\section{INTRODUCTION}

Since its introduction in 1998, the golden rule has played a key role underpinning the U.K. fiscal framework. The golden rule stipulates that over the economic cycle, the government should borrow only to invest and not to fund current spending. More specifically, it requires the current budget to be in balance or surplus on average over the economic cycle. The rationale for focusing on the current budget is to protect investment spending, which is particularly important in the United Kingdom given significant infrastructure needs. The rationale for targeting "over the cycle" is to allow automatic stabilizers to work without jeopardizing long-term fiscal sustainability. The present formulation of the rule allows fiscal performance to be tested ex-post as to whether the golden rule has been met. By identifying the cycles and in turn the cyclical effects on the public finances, it also aims to assess the underlying structural fiscal position.

While the golden rule is widely seen as having constrained discretion, the "over the cycle" formulation of the rule gives rise to two drawbacks. First, the automatic stabilizers may not be allowed to operate fully because procyclical fiscal tightening may be required toward the end of a cycle to ensure that the golden rule is met. Second, the ex-post test of fiscal performance requires precise dating of the economic cycle, which leads to controversy since alternative methodologies can yield significantly different interpretations of the cycle.

Against this background, the objective of this paper is to investigate an alternative modus operandi for the golden rule that would address both of these drawbacks. Specifically, the paper examines the merits of making the fiscal rule exclusively forward-looking and independent of the dating of the cycle by aiming for current balance or better over a rolling time horizon. For this purpose, the paper will compare fiscal performance under different ways of implementing the golden rule using a simple open economy model of the U.K. economy, which is subject to various stochastic shocks. In analyzing the results, the paper focuses on the following three issues:

- How does the uncertainty associated with precise dating of the cycles affect the implementation of fiscal policy? The paper will illustrate the considerable difficulties in planning and implementing fiscal policy over the cycle even when the cycles are perfectly observable ex-post.

- How big is the risk of procyclicality in fiscal policy implementation? The paper will show that the alternative formulation of the golden rule reduces the volatility of output and prices by removing the cycle from the operational target of the golden rule. In turn, this will reduce the risk of procyclical fiscal policy. However, this is accompanied by a slight increase in the variability in the ratio of debt to GDP over the cycle. 
- $\quad$ To what extent are the results robust? The paper compares performance across a range of two- to five-year rolling time horizons to check the robustness of the simulation results.

The paper is organized as follows. Section II provides a brief description of developments leading to the introduction of the golden rule and illustrates the difficulties associated with a strict implementation of the rule in practice. Section III provides a brief overview of the structural macroeconomic model used in the paper to simulate performance of alternative fiscal rules in the presence of various stochastic shocks. More details of the model and the estimation results are presented in the appendices. Section IV summarizes the key simulation results. Section V provides some concluding remarks.

\section{BACKGROUND}

The significant deterioration in the underlying fiscal position in the late 1980s contributed to the current design of the fiscal framework. U.K. Treasury (1997) explains that the large slippage in the public finances during the period FY1989/90-FY1993/94 was due in part to a misjudgment. ${ }^{1}$ The sizeable improvement in the public finances in the second half of the 1980s was thought to reflect mostly structural factors, but the sharp weakening in the budget balance during the subsequent economic downturn suggested that cyclical factors may have played more of a role in this fiscal improvement. In addition, the medium-term orientation of fiscal policy lacked a clear and stable objective that allowed an ex-post evaluation of its performance. To address past problems that contributed to economic instability and a neglect of public investment, the government introduced a new fiscal framework over the economic

Figure 1. Fiscal Developments
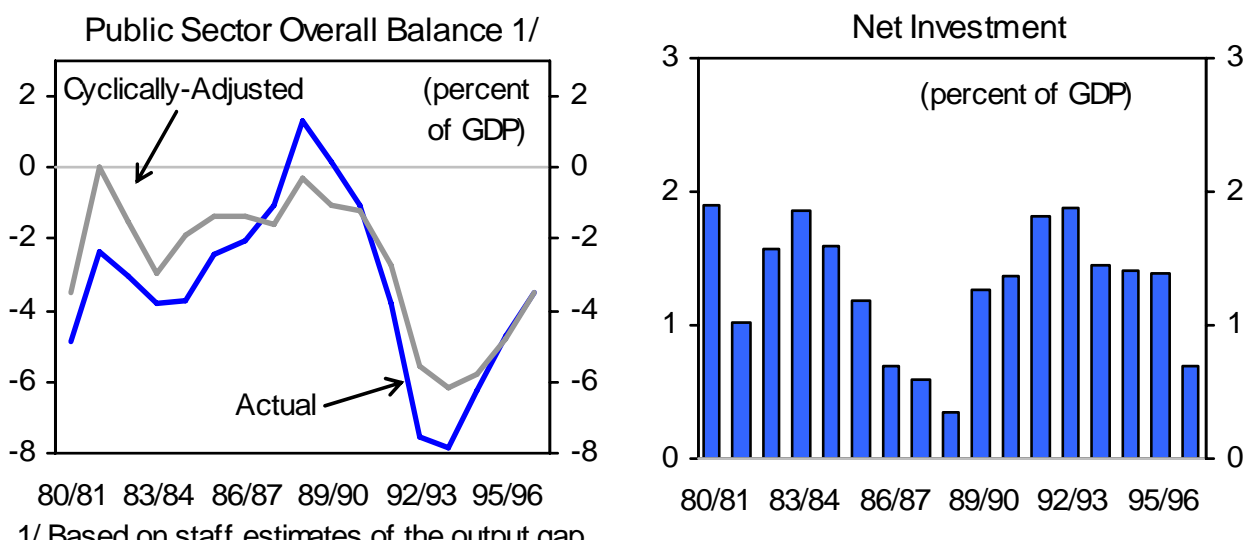

\footnotetext{
${ }^{1}$ The fiscal year runs from April to March.
} 
cycle based on two pillars: (i) fiscal rules to ensure sustainability while allowing short-run flexibility, with the "golden rule," which prohibits current spending from being financed through borrowing over the economic cycle, and a "sustainable investment rule," which requires public sector net debt be kept over the economic cycle at a "stable and prudent" level, currently interpreted as below 40 percent of GDP; and (ii) a multiyear spending framework that sought to increase predictability and avoid a historical bias against capital spending. With a greater role being played by cyclically adjusted indicators in setting the stance of fiscal policy, the golden rule aims at enhancing macroeconomic stability by allowing the automatic stabilizers to operate in response to cyclical variations. An objective ex-post evaluation of fiscal performance at the same time was expected to add accountability and credibility to fiscal policy.

However, an ex-post assessment of observance of the golden rule requires precise dating of the economic cycle, which in practice involves a considerable degree of imprecision. First, there are different views about how to define cycles. ${ }^{2}$ A traditional approach is based on identifying the turning points in the level of output. Alternatively, cycles can be identified by decomposing the level of output between trend and cyclical factors, which is closely associated with measuring the output gap. Second, there is a wide range of alternative approaches to estimating the cycles. These include statistical filtering such as the HodrickPrescott (HP) filter, the production function approach, the turning point approach following the principles laid out by NBER practices, and the U.K. Treasury's on-trend-point approach. Different methodologies can yield significantly different estimates of the dating of the cycles; hence, judgment plays an important role.

Although judgment is necessary, there may be a perception of conflict of interest in the way the cycle is currently defined. The dating of the economic cycle is critical to measuring fiscal performance against the golden rule. At present, the Treasury not only determines the economic cycle but also conducts the self assessment as to whether the fiscal rules have been met or not over a cycle. In 2005, following important revisions in the national account data, the Treasury redefined the economic cycle by moving back the start of the cycle from 1999 to 1997 . While this redating was seen as technically defensible-as confirmed by the audit conducted by the National Audit Office (NAO) — it raised questions about the possible manipulation of the rules as the new dates pulled a sizable current surplus in 1998 into the present cycle, effectively providing room to delay adjustment without imperiling observance of the golden rule. ${ }^{3}$

\footnotetext{
${ }^{2}$ U.K. Treasury (2005) provides a summary of existing methods to identify and estimate economic cycles.

${ }^{3}$ The NAO, an independent body that reports directly to Parliament, audits key assumptions and conventions underpinning the fiscal projections. Following the redefinition of the cycle in 2005, the Treasury asked the NAO to audit the decision to revise the start of the economic cycle from FY1999/2000 to FY1997/98. The NAO found that the Treasury's methodology and the decision to be reasonable.
} 
Under the new fiscal framework, the current budget position since FY2002/03 has swung from a large surplus to deficit. The bulk of this deterioration was structural and primarily reflected planned increases in spending on public services, especially in health, education, and transport. This large fiscal expansion has been consistent with the U.K. fiscal framework because of the current surpluses accumulated during the early stage of the cycle. However, with persistent current deficits subsequently, these margins narrowed significantly raising concerns about the risk of breaching the golden rule. ${ }^{4}$ While there is a consensus that the golden rule has contributed to constraining discretion in the public finances, experience so far motivates exploring alternative ways of implementing the fiscal rule that place less emphasis on the definition of the cycle.

Figure 2. The Golden Rule and the Economic Cycle
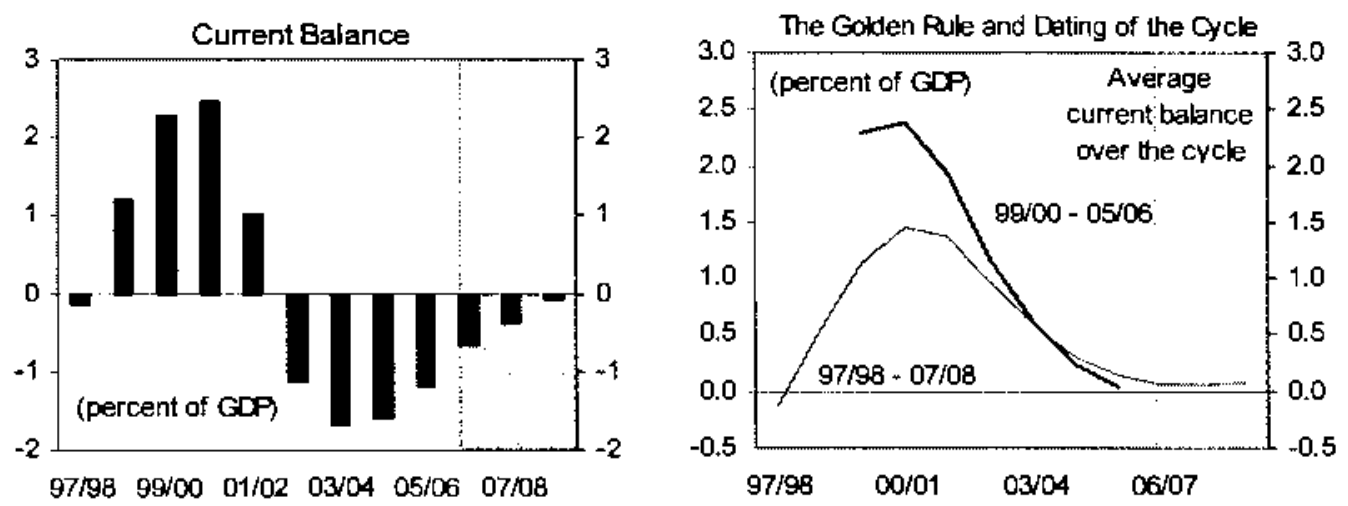

In addition, the reduced volatility in U.K. output in the 1990s suggests that the effects of the economic cycle on the public finances may have weakened. Output volatility, given by the standard deviation of the output gap, declined from 2 to $1 / 2$ over the past decade. This substantial improvement in stability in part reflects the strengthening of macroeconomic policy frameworks in the United Kingdom, as well as structural factors, including the increased flexibility of labor, product, and financial markets. In an economy that displays such small cyclical variation, it is increasingly difficult to justify the need for setting the fiscal rule explicitly over the economic cycle.

Output Gap 1/

(in percent of potential output)

\begin{tabular}{lcc}
\hline & Average & St Devation \\
\hline $1978-1993$ & -0.7 & 2.0 \\
$1994-2006$ & 0.1 & 0.5 \\
\hline
\end{tabular}

1 Staff estimates based on quarterly real GDP data.

\footnotetext{
${ }^{4}$ Progress against meeting the golden rule is measured by the average balance on the current budget as a percentage of GDP since the start of the cycle.
} 


\section{The Model AND THE Simulation}

The paper simulates the performance of an alternative way to implement the golden rule when the economy is subject to various dynamic stochastic shocks. For this purpose, a small open-economy "New Keynesian” model with rational expectations is used. The model is specified in gap and rate-of-change terms so that, under inflation targeting, all variables are stationary. For simulation purposes, the equilibrium values for the real interest rate, and the real exchange rate are assumed to be time invariant. The U.K. portion of the model consists of five key behavioral equations given by the following:

(1) Aggregate demand (IS function)

$\operatorname{ygap}_{t}=\beta_{1} \cdot \operatorname{ygap}_{t-1}+\beta_{2} \cdot \operatorname{ygap}_{t+1}+\beta_{3} \cdot \operatorname{rrgap}_{t-1}+\beta_{4} \cdot \operatorname{zgap}_{t-1}+\beta_{5} \cdot \operatorname{ygap}_{t}^{*}-\beta_{6} \cdot \mathrm{FBgap}_{t-1}+\varepsilon_{t}^{\text {ygap }}$

(2) Inflation

$\pi_{t}=\delta_{1} \cdot \pi_{t+4}^{4}+\left(1-\delta_{1}\right) \cdot \pi_{t-1}^{4}+\delta_{2} \cdot \operatorname{ygap}_{t-1}+\delta_{3} \cdot \Delta z_{t}+\varepsilon_{t}^{\pi}$,

(3) Real exchange rate

$z_{t}=\varphi \cdot z_{t+1}+(1-\varphi) \cdot z_{t-1}+\left(r r_{t}-r r_{t}^{*}\right) / 4+\varepsilon_{t}^{z} / 4$,

(4) Monetary policy reaction function

$r s_{t}=\alpha_{1} \cdot r s_{t-1}+\left(1-\alpha_{1}\right) \cdot\left(r r_{-} e q_{t}+\pi_{t}^{4}+\alpha_{2} \cdot\left(\pi_{t+4}^{4}-\pi^{T}\right)+\alpha_{3} \cdot y g a p_{t}\right)+\varepsilon_{t}^{r s}$, and

(5) Fiscal policy reaction function

FBgap $_{t}=\theta_{1} \cdot \operatorname{ygap}_{t-1}-\theta_{2} \cdot \operatorname{Dgap}_{t+1}+\varepsilon_{t}^{F B g a p}$.

where ygap is the output gap, $r r$ is the real interest rate, $z$ is the real exchange rate, $F B$ is the fiscal balance, $\pi$ is CPI inflation, $r s$ is the nominal policy rate, $D$ is the government debt, and Dgap is the deviation from the government's debt target $\mathrm{D}^{*}$. For this exercise, debt is defined as the cumulative fiscal balance. In addition, $\Delta$ is the first difference operator, * denotes foreign variables, $\varepsilon$ denotes error terms, and parameters are given by the $\beta_{s}, \delta_{s}, \varphi$, and $\alpha_{s}$. The foreign sector is characterized by the similar behavioral equations, but there is no endogenous fiscal policy reaction function in the foreign sector.

The fiscal rule is designed to simultaneously ensure a consistently countercyclical fiscal stance and achieve a stable public debt target. As indicated in equation (5) above, the fiscal policy reaction function sets the path for the fiscal balance (in percent of GDP) as a function of the output gap (to allow the automatic stabilizers to function) and a discretionary policy term, which aims at achieving a specific policy objective. By construction, the automatic stabilizers take effect regardless of the modus operandi of the fiscal rule, however, their effects can be either offset or complemented by the size and the direction of discretionary policy. The rest of the world (ROW) portion of the model consists of equations for aggregate demand, inflation, and the monetary policy reaction function. 
The model is estimated using the Bayesian technique for a sample period of 1992:Q42006:Q4. The simple model abstracts from many important features of the economy, especially the supply side, and it does not solve endogenously for the equilibrium values for the real exchange rate or potential output growth. Nevertheless, the model incorporates the key channels of monetary policy transmission and, with the introduction of fiscal policy, it captures the effects of coordination between monetary and fiscal policy. Additional details of the model and the estimation results are presented in Appendix I.

Using the estimated parameters, the model can be simulated under stochastic shocks that fit the historical U.K. data. The economy is hit by seven different stochastic shocks in every period, representing shocks to output, prices and interest rates in the U.K. and the ROW portion of the model, and to the real exchange rate. These shocks are drawn from a normal distribution with mean 0 and the standard deviation equivalent to the estimated value in the model. The simulation starts from the steady-state solution of the model. To evaluate performance of alternative specifications of the fiscal rule, simulations are conducted over 1000 draws that last for 100 quarters. ${ }^{5}$ Each draw can be considered as containing a sequence of 100 model-based forecasts.

The simulation for each period is conducted in three steps (see flow chart below). The first step involves updating the model-based macroeconomic forecasts consistent with achieving the inflation target in response to new stochastic shocks at date $t$, given the state of the

Figure 3. Sequence of Decisions in Each Period

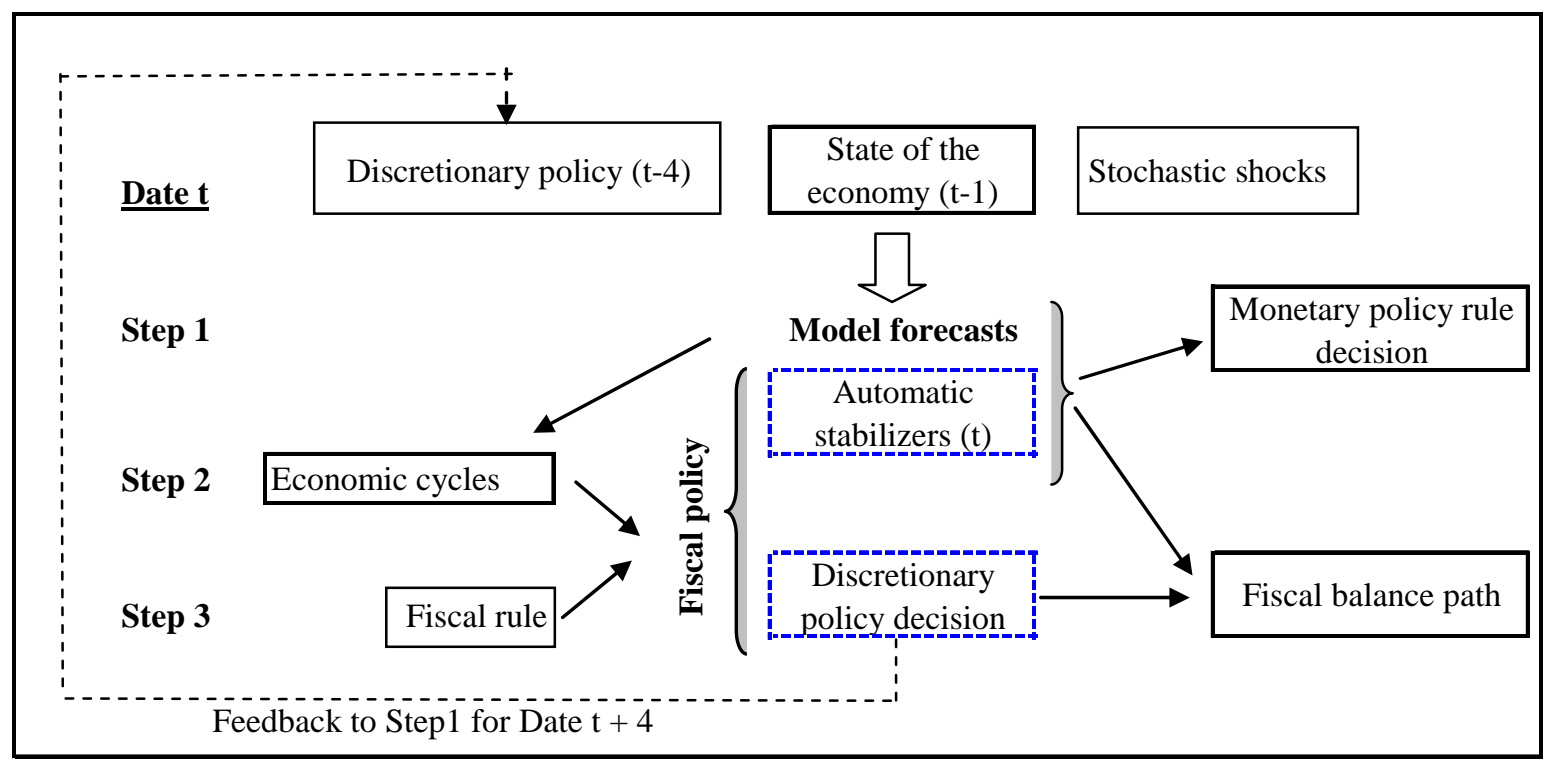

\footnotetext{
${ }^{5}$ The model-generated moments show stable properties with 500 draws, which ensures that 1,000 draws are sufficient to support statistical inference.
} 
economy at the previous date $t-1$ (and the latest discretionary fiscal policy decisions available by the fiscal authorities). In setting a path for the policy interest rate, the monetary authorities take into account the effects of the automatic fiscal stabilizers in response to changes in the output gap. The second step involves identifying the economic cycles_-for both ongoing and future cycles. Because of the new shocks, the amplitude and the ending date of the current cycle may have shifted. To make the simulation more illustrative, the paper assumes that expost the output gaps are fully observable and perfectly measurable. Given the economic cycles, the third step involves adjusting the current and future path for the fiscal balance with the objective of meeting the fiscal rule being tested. Because the automatic stabilizers are already in place, any fiscal adjustment requires changes in the discretionary component of fiscal policy. Finally, the current period's outcome, forecast, and any adjustment to fiscal policy become available to the policymaker in the subsequent period and the three-step simulation starts again. While the frequency with which monetary authorities revise policy settings based on new inflation forecasts is high, fiscal policy tends to be revised only on an annual basis. ${ }^{6}$ Taking this into account in the simulations, the discretionary component of fiscal policy is updated only once a year. Until the next fiscal forecast becomes available, the monetary policy decision continues to base on the latest available information from the fiscal authorities.

\section{A. The Economic Cycle-Definition and Identification}

The U.K. Treasury defines cycles by identifying on-trend points in the cycle. As described above, the use of the level of the output gap to define cycles is different from the standard methodology that uses the level of output to detect turning points. However, this paper follows a similar approach to the Treasury's by identifying the crossing points between trend and actual output, specifically where there is no output gap in the economy. By definition, in each cycle, the output gap crosses the zero line three times. In line with the Treasury's approach, to select only those "decisive” crossing points and exclude those temporary movements around the zero output gap, the paper requires four consecutive quarters of either a positive or negative output gap following a change in its sign in order to define crossing points. ${ }^{7}$

Applying this definition to estimates of the U.K. output gap, three cycles can be identified during the period since the late 1970s, 1978:Q1 to 1987:Q2, 1987:Q3 to 1997:Q3, and

\footnotetext{
${ }^{6}$ In the United Kingdom, the Monetary Policy Committee meets once every month to take a policy interest rate decision, with a quarterly Inflation Report that contains MPC inflation forecast. The U.K. Treasury publishes Pre-Budget Report in end year followed by Budget in March/April. Usually there are no major changes in fiscal policy between two budget documents.

${ }^{7}$ This implies the shortest cycle would be eight quarters (two years).
} 
1997:Q4 to 2003:Q2. ${ }^{8}$ The chart below (left) suggests that the cycles have become shorter and their amplitude shallower over time. In the simulations conducted over 1,000 draws that last for 100 quarters ( 25 years), the average length of each cycle is about 27 quarters. The result is very similar to other findings in the literature. ${ }^{9}$

Figure 4. Economic Cycles
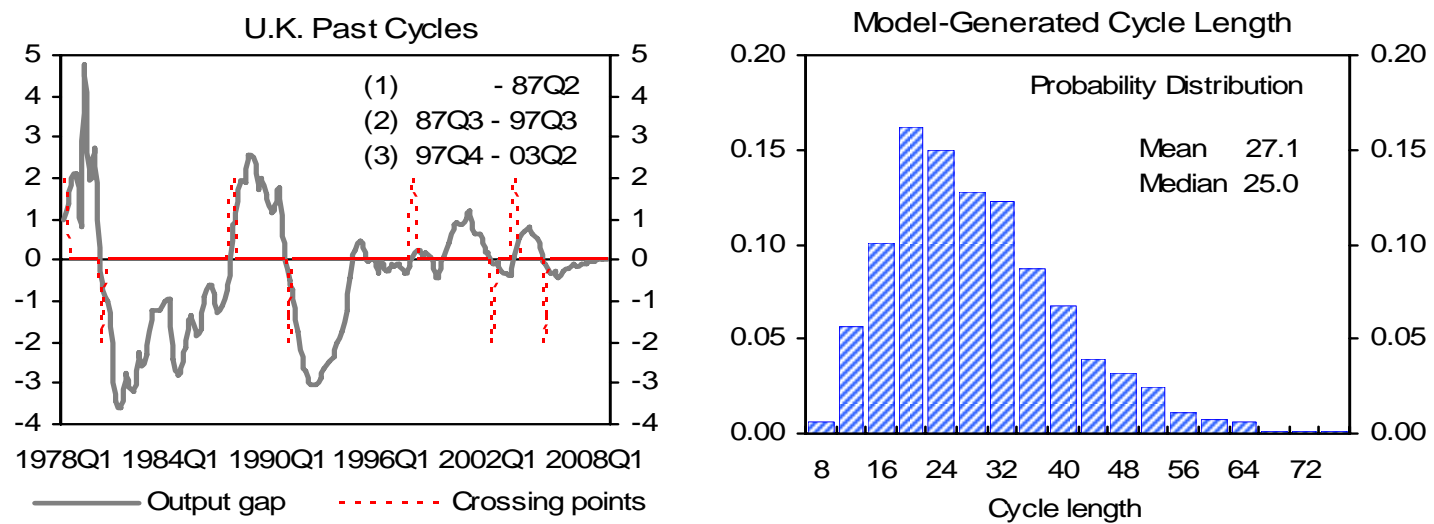

\section{B. Fiscal Balances}

Fiscal balances are determined by two components, the automatic stabilizers and discretionary policy. The automatic stabilizers ( Ast $_{t}$ ) are computed using the same elasticities with respect to contemporaneous and lagged output gaps estimated by the Treasury in 2003. ${ }^{10}$ The discretionary component aims at achieving a specific policy objective, given the effects of the automatic stabilizers, to meet the fiscal rule. Because there are no differences in the effects of the automatic stabilizers, any differences in fiscal policy stems from the discretionary component. In the model the fiscal balance is specified in gap terms, defined as the deviation from the equilibrium fiscal balance. In the context of the United Kingdom, the equilibrium overall fiscal balance is calibrated at -2 percent of GDP, which is consistent with maintaining a zero current balance and 2 percent of GDP in net investment so as to satisfy long-term investment needs. At the same time, this is consistent with stabilizing public sector net debt at 40 percent of GDP. Finally, debt is defined as the

\footnotetext{
${ }^{8}$ The U.K. Treasury identifies 1986:Q2 and 1997:H1 to be the on trend points.

${ }^{9}$ For example, see Artis (2002).

${ }^{10}$ The estimates based on the empirical analysis suggest that a 1 percent increase (decline) in output relative to trend reduces (increases) the elasticity of the current balance with respect to output is 0.7 , of which 0.5 from contemporaneous and 0.2 from lagged output gaps. These coefficients are obtained by regressing spending and revenue ratios to GDP on estimates of contemporaneous and lagged output gaps.
} 
cumulative sum of the fiscal balance gaps $(\mathrm{CumFB}) .{ }^{11}$ Similarly to other variables, the starting value of the fiscal balance (gap) is zero.

The fiscal balance under the current "over the cycle" formulation of the golden rule is specified as follows:

FBgap $_{t}=$ Ast $_{t}-\frac{E\left[\Delta \operatorname{CumFB}_{T-t}\right]+\mathrm{CumFB}_{\mathrm{t}-1}}{T-t}$

Ast $_{t}=0.5 * y g a p_{t}+0.2 * y g a p_{t-1}$

where ygap $_{t}$ and ygap $_{t-1}$ are contemporaneous and lagged output gaps. Under the golden rule, discretionary policy at time $t$ is determined as a function of how many quarters are forecast to be left to the end of the cycle ( $T-t$, where $T$ is the end of the cycle), the size of debt or surplus incurred since the beginning of the cycle $\left(\mathrm{CumFB}_{t-1}\right)$, and the expected change in the cumulative balance till the end of the cycle $E\left[\Delta C u m F B_{T-t}\right]$. The paper assumes that any adjustment required to achieve balance or surplus in the current budget over the economic cycle is introduced smoothly and gradually over the remainder of the cycle. To introduce a non-negativity constraint in the cumulative balance as required in the golden rule, the fiscal authorities are assumed to introduce measures necessary to achieve balance in the end if they face a cumulative deficit. However, the fiscal balance is not allowed to deteriorate sharply at the end of the cycle because of "overspending" at the last moment to offset a cumulative surplus.

Alternatively, the operational target of the golden rule is changed from current balance or better "over the cycle" to aiming for current balance or better "over a forward-looking rolling horizon." Specifically, the paper examines the range between two- and five-year rolling horizons. In evaluating fiscal performance of such forward-looking rule, the paper will focus on the three-year horizon. However, as explained in more detail below, simulation results are robust to different time horizons. The alternative modus operandi-called here the "forwardlooking rule"-is defined as the following:

$$
\begin{aligned}
& \text { FBgap }_{\mathrm{t}+\mathrm{j}}=\text { Ast }_{\mathrm{t}+\mathrm{j}}-\frac{\mathrm{j}}{12} * \mathrm{E}\left(\mathrm{FBgap}_{\mathrm{t}+12}\right) \quad \text { for } \mathrm{j}=[0,12] \\
& \text { FBgap }_{\mathrm{t}+12+\mathrm{n}}=A s t_{\mathrm{t}+12+\mathrm{n}}-\frac{\mathrm{E}\left(\Delta \operatorname{CumFB}_{\mathrm{t}+28}\right)+\operatorname{CumFB}_{\mathrm{t}+12}}{16} \quad \text { for } \mathrm{n}=[0,16]
\end{aligned}
$$

\footnotetext{
${ }^{11}$ Note that a positive (negative) gap in the fiscal balance implies a surplus (deficit). Thus, increase (decline) in CumFB in this model is equivalent to a decline (increase) in debt.
} 
The specification of the automatic stabilizers ( $A s t_{t}$ ) is the same as the current "over the cycle" means of implementing the golden rule. The objectives of the forward-looking rule are twofold. It aims at achieving a fiscal balance three-year ahead $\left(F B g a p_{t+12}\right)$ and over the next four years eliminates any projected debt gap ( $\mathrm{E}\left(\Delta C u m F B_{t+28}\right)$. Similarly to the golden rule, fiscal adjustments are introduced gradually. For example, if a fiscal deficit of 1 percent of GDP is projected 12 quarters ahead $\left(F_{B g a p}{ }_{t+12}=-1.0\right)$, one-twelfth of the needed fiscal adjustment is introduced each successive quarter. To allow for the non-negativity constraint, if the expected fiscal balance three years ahead is in surplus, fiscal policy is projected to let just the automatic stabilizers operate for at least four quarters until the fiscal projections are revised given new developments.

\section{Simulation Results}

The model results suggest that the uncertainty associated with balancing over the cycle is significantly large even when cycles are perfectly observable ex-post. A cycle that is initially forecast to begin with a strong period of upswing can change its course to a downturn following adverse shocks to the economy. During a cycle, as different shocks hit the economy, the projected end of the cycle may shift unexpectedly and continuously. In addition, depending on the relative size and the composition of the shocks, downswings and upswings can differ in terms of their intensity or duration, with important implications for the public finances. As a result, an attempt to meet a particular fiscal objective "over the cycle" may result in unnecessary fluctuations in fiscal policy and hence in the real economy.

The uncertainty about the end of the cycle has significant implications for achieving current balance in the present formulation of the golden rule. Simulations suggest that, under the "over the cycle" formulation of the golden rule, the 95 percent confidence interval for the cumulative balance at the end of the cycle is in the range of \pm 1 percent of GDP. This implies that the golden rule would be breached nearly half of the time. More specifically, the resulting distribution of the cumulative balance at the end of the cycle suggests that there is a 45 percent probability that the cumulative balance falls into deficit. This is because sometimes cycles end unexpectedly before any required adjustment can occur. Although the likelihood of missing by a large margin— defined as more than $1 / 2$ percentage point of GDP—is relatively low, at about 15 percent. The high frequency of missing could damage the credibility of the fiscal rule.

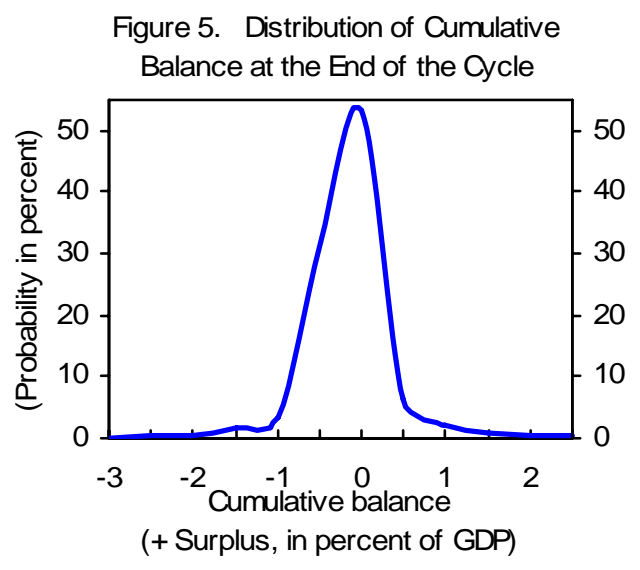


Thus, in the "over-the-cycle" formulation, there is an important risk that fiscal policy becomes increasingly procyclical toward the end of the cycle. Cyclical consideration of the golden rule calls for accumulating margins (cumulative surpluses) during the good times so as to compensate for deficits during the bad times. However, if the projected end of the cycle is suddenly nearer, or if the downswings are longer or more intense than expected, achieving current balance or better over the cycle may require considerable fiscal adjustment over a short period toward the end of the cycle. Large fiscal consolidation when there is slack in the economy could deepen the downturn. Simulation results suggest that in trying to achieve balance or better in the current balance over the cycle, the risk of such procyclicality increases progressively as the cycle approaches the end (see table below). While there is virtually no procyclical fiscal policy during the early stage of the cycle, in the final stage, fiscal policy becomes procyclical at some point by more than $1 / 2$ percentage points of GDP in over half of the 2,767 simulated cycles. ${ }^{12}$ In particular, in about 12 percent of the simulated cycles, fiscal policy was procyclical during the entire last fourth of each cycle. In contrast, under the alternative forward-looking three-year rule, such risk is virtually zero. This is because early overperformance cannot be used to offset later underperformance.

Table 1. Golden Rule: Procyclical Fiscal Policy During the Cycle 1/

\begin{tabular}{lccrr}
\hline & Quartile1 & Quartile2 & Quartile3 & Quartile4 \\
\cline { 2 - 5 } & Beginning $=======>$ End of the Cycle \\
\hline & (in percent of total simulated cycles) & & \\
No procyclicality & 93.1 & 87.3 & 66.3 & 44.2 \\
Procyclicality & 6.9 & 12.7 & 33.7 & 55.8 \\
ow. By more than a half of the time in quartile & 0.7 & 4.8 & 18.8 & 36.8 \\
ow. 100 percent procyclical during quartile & 0.1 & 0.7 & 7.0 & 11.6 \\
\hline 1/ Percentage of the time in each quartile fiscal policy is procyclical by more than 1/2 percentage point of GDP \\
per year.
\end{tabular}

By reducing the risk of procyclical fiscal policy, the volatility of output and prices can be reduced. A comparison of the standard deviation of output and inflation with and without fiscal policy suggests that fiscal policy plays an important role in lowering the volatility of the economy (see table below). This is primarily attributed to the operation of the automatic stabilizers. Both the balance over the cycle rule and the forward-looking rule add stability to economic activity. However, because of procyclical fiscal policy at times toward the end of a cycle using a balance "over the cycle" formulation, the forward-looking formulation at a three-year horizon enhances economic stability by about 5 to 7 percent.

\footnotetext{
${ }^{12}$ To focus only on the risk of procyclical policy with large adverse impact on the real economy, the paper limits the term procyclical only when the difference between the realized fiscal balance and the level implied by the automatic stabilizers (in absolute value terms) is more than 0.5 percentage point of GDP.
} 
Table 2. Comparison of Economic Performance Over the Cycle

\begin{tabular}{|c|c|c|c|c|}
\hline & $\begin{array}{r}\text { Automatic } \\
\text { Stabilizer }\end{array}$ & $\begin{array}{c}\text { Forward- } \\
\text { looking }\end{array}$ & $\begin{array}{r}\text { Over the } \\
\text { cycle }\end{array}$ & $\begin{array}{r}\text { No Fiscal } \\
\text { policy }\end{array}$ \\
\hline \multicolumn{5}{|c|}{ (Average over the cycle) } \\
\hline \multicolumn{5}{|l|}{ Standard deviation } \\
\hline Output & 0.81 & 0.80 & 0.86 & 1.08 \\
\hline Prices & 0.72 & 0.71 & 0.74 & 0.80 \\
\hline Fiscal balance & 0.56 & 0.57 & 0.58 & $\ldots$ \\
\hline Cumulative balance & 3.33 & 3.31 & 2.28 & $\ldots$ \\
\hline \multicolumn{5}{|c|}{ (in percent of GDP) } \\
\hline \multicolumn{5}{|c|}{ Cumulative balance at the end of the cycle } \\
\hline Average & & 0.51 & 0.07 & ... \\
\hline Standard deviation & & 2.33 & 0.47 & $\ldots$ \\
\hline \multicolumn{5}{|c|}{ Change in cumulative balance over the cycle } \\
\hline Average & 0.03 & 0.26 & 0.03 & $\ldots$ \\
\hline Standard deviation & 1.91 & 1.86 & 0.60 & $\ldots$ \\
\hline
\end{tabular}

Implementing the golden rule at a forward-looking rolling horizon gets rid of procyclicality, but imposes a somewhat looser constraint on debt over any given cycle. Assuming the simulation starts with the level of public sector net debt at 40 percent of GDP, a comparison of the standard deviation of the cumulative balance (the debt-to-GDP ratio) over the cycle suggests that under the golden rule as it is currently implemented, 95 percent of the time net debt would remain within \pm 5 percentage points of the debt ceiling (between 35 and 45 percent of GDP). In contrast, the fluctuation is larger when a three-year ahead rolling horizon is used. Under this alternative, net debt would be within \pm 7 percentage points of GDP from the debt ceiling 95 percent of the time. Despite slightly larger movement in the debt level, the simulation also suggests that on average over the cycle the level of net debt declines by 0.3 percentage points of GDP under the forward-looking three-year alternative. ${ }^{13}$ This is because of the asymmetric implementation of this rule. Specifically, fiscal policy is solely governed by the operation of the automatic stabilizers if the economy is projected to be above trend three years ahead and surpluses are not spent.

Higher debt volatility under the forward-looking formulation of the golden rule could be reduced by introducing a debt band around the equilibrium debt-to-GDP ratio. Fiscal policy continues to aim at achieving a fiscal balance three years ahead, but once the cumulative balance goes outside the band, it is required to take more aggressive measures to ensure that the cumulative balance returns within the band. This can be specified by adding a third term in equation (7) that constrains the fiscal balance depending on the level of the cumulative

\footnotetext{
${ }^{13}$ Note that cumulative debt is defined as the cumulative sum of the fiscal balance, where positive implies a surplus, hence decline in debt.
} 
balance $(C U m F B)$ and the width of the band $(\bar{D})$ - the maximum deviation from the equilibrium debt-to-GDP ratio.

FBgap $_{\mathrm{t}+\mathrm{j}}=$ Ast $_{\mathrm{t}+\mathrm{j}}-\frac{\mathrm{j}}{12} * \mathrm{E}\left(\right.$ FBgap $\left._{\mathrm{t}+12}\right)+\mathrm{D}_{1} * \mathrm{D}_{2} \quad$ for $\mathrm{j}=[0,12]$

where $D 1=1$ when $|C u m F B|>\bar{D}$ and $D 1=0$ otherwise, and $D 2$ is the adjustment effort. For simplicity, $D 2$ is set to 1 , thereby whenever the cumulative balance goes outside the band, a fiscal measure amounting to 1 percent of GDP is automatically introduced.

Simulation results show that a debt band with a width of \pm 3 percentage points of GDP lowers debt volatility under the forward-looking formulation to \pm 5 percentage points, but adds back a small risk of procyclicality (Table 3). This is because there are sometimes conflicts in achieving a flow target at a three-year horizon and at the same time meeting the stock target. Nonetheless, the risk of procyclical fiscal policy is considerably smaller than in the "over the cycle” formulation of the golden rule.

Table 3. Forward-looking Rule with a Debt Band: Procyclical Fiscal Policy During the Cycle 1/

\begin{tabular}{|c|c|c|c|c|}
\hline & Quartile1 & Quartile2 & Quartile3 & Quartile4 \\
\hline & \multicolumn{4}{|c|}{ Beginning ===========> End of the Cycle } \\
\hline \multicolumn{5}{|c|}{ (in percent of total simulated cycles) } \\
\hline No procyclicality & 96.4 & 95.7 & 94.5 & 92.3 \\
\hline \multicolumn{5}{|l|}{ Procyclical } \\
\hline By more than a half of the time in quartile & 0.5 & 0.9 & 1.4 & 2.0 \\
\hline ow. $100 \%$ procyclical & 0.1 & 0.1 & 0.2 & 0.2 \\
\hline
\end{tabular}

Simulation results are robust to different time horizons used to specify alternative ways of implementing the golden rule. A comparison of fiscal performance at a two-year ahead or five-year ahead rolling time horizons suggests that the volatility of output and prices remain broadly unchanged from the result under the three-year time horizon. Ex-ante, the projected fiscal balance is different as the two-year ahead rule aims at achieving current balance or better in two years, while the five-year rule would aim for five-year ahead. However, ex-post, the realized fiscal balances are broadly similar with some small differences in the cumulative balance over the cycle. The volatility in the cumulative balance over the cycle remains large, but because the two-year rule starts introducing any required adjustment earlier, on average there is somewhat larger reduction in debt over time. 
Table 4. Alternative Rule: Different Horizons

\begin{tabular}{lrrr}
\hline & 2-year rule & 3-year rule & 5-year rule \\
& & & \\
& (Average over the cycle) & & \\
Standard deviation & 0.82 & 0.80 & 0.81 \\
Output & 0.71 & 0.71 & 0.71 \\
Prices & 0.55 & 0.57 & 0.56 \\
Fiscal balance & 3.15 & 3.31 & 3.36 \\
Cumulative balance & (in percent of GDP) & & \\
Change in cumulative balance over the cycle & 0.43 & 0.26 & 0.11 \\
$\quad$ Average & & & \\
\hline
\end{tabular}

\section{CONCLUDING REMARKS}

The analysis presented in this paper suggests that making formulation of the golden rule exclusively forward-looking and independent of the dating of the cycle would enhance macroeconomic stability. Using an open economy model of the U.K. economy, it can be demonstrated that changing the modus operandi of the golden rule from current balance or better "over the cycle" to aiming for current balance or better "at a two-five-year ahead rolling horizon" would reduce the volatility of output and prices. This is because with the "over the cycle" formulation, there is a risk that, if the projected end of the cycle is suddenly nearer, a considerable fiscal adjustment over a short period may be required. Simulations suggest that the risk of a procyclical fiscal adjustment (defined as a procyclical fiscal adjustment of at least $1 / 2$ percentage point of GDP per year during the last quartile of a cycle that adds to domestic demand when GDP is above trend or subtracts from it when GDP is below trend) is about 12 percent. The risk of procyclicality is virtually zero when the golden rule is implemented "at a two-five-year ahead horizon" instead. Using the forward-looking rule increases the variability of the debt-to-GDP ratio slightly from \pm 5 to \pm 7 percentage points of GDP, but this could be mitigated by introducing a debt band around the equilibrium debt-to-GDP ratio.

The analysis conducted in this paper is subject to a number of caveats. The model specification is simple and abstracts from other important issues in assessing fiscal policy. For example, the model does not explicitly take into account movements in asset prices. This may be particularly important for the United Kingdom given the increasing importance of the financial sector in economic activity. Also, while the simulations use estimated parameters and shocks that fit the historical U.K. data, the true parameters may be different going forward.

In addition, the successful implementation of a forward-looking rule still depends on unbiased judgments about the economy's prospects. Unless macroeconomic projections are unbiased, there is a risk that fiscal slippages could accumulate rapidly, increasing the debt burden. Indeed, without an ex-post test of fiscal performance, (however imperfect), the credibility of ex-ante forecasts is arguably even more important. 


\section{References}

Artis, M., 2002, Dating the Business Cycle in Britain, CGBCR Discussion Paper Series, available at http://www.ses.man.ac.U.K./cgbcr/discussi.htm.

Berg, A., P. Karam, and D. Laxton, 2006, Practical Model-Based Monetary Policy Analysis-How-To Guide, IMF Working Paper No. 06/81 (Washington, D.C.: International Monetary Fund).

Emmerson, C., C. Frayne, and S. Love, 2004, Updating the U.K.'s Code for Fiscal Stability, IFS Working Paper No. 04/29.

U.K. Treasury, 1997, Fiscal Policy: Lessons from the Last Economic Cycle, available at http://www.hm-treasury.gov.U.K./mediastore/otherfiles/lessons.pdf. , 1999, Fiscal Policy: Public Finances and the Cycle, available at http://www.hmtreasury.gov.uk/media/415/CB/cycles.pdf.

, 2003a, End of Year Fiscal Report, available at http://www.hmtreasury.gov.uk/media/324/70/end_of_year_352.pdf. , 2003b, Evidence on the UK Economic Cycle, available at http://www.hmtreasury.gov.uk/media/2E6/A5/economic_cycles190705.pdf.

Honjo, K., and B. Hunt, 2006, Stabilizing Inflation in Iceland, IMF Working Paper 06/262 (Washington, D.C.: International Monetary Fund).

Kell, M., 2001, Assessment of Fiscal Rules in the United Kingdom, IMF Working Paper No. 01/91 (Washington, D.C.: International Monetary Fund).

Koeva, P., 2003, The Implementation of the Golden Rule, (Washington, D.C.: International Monetary Fund).

Van den Nord, P., 2000, The Size and Role of Automatic Fiscal Stabilizers in the 1990s and Beyond, OECD Working Paper No. 230. 


\section{Appendix I. Data Description and Sources}

This appendix describes the data used in the simulations.

Output gap (percentage points): Staff estimates using quarterly real GDP series from 1992:Q4 to 2006:Q2 based on a production function approach.

Source: GDP (ONS).

Consumer prices: Synthetic combination between RPIX and CPI using quarterly RPIX index from 1992:Q1 to 2003:Q4 and the rate of change from CPI index from 2004:Q1 onwards.

Source: ONS.

Exchange rate: Quarterly effective exchange rate index 1992:Q4 to 2006:Q2.

Source: Bank of England (BoE)

Real exchange rate: Calculated using domestic and foreign inflation and nominal effective exchange rate from the BoE. Equilibrium values are exogenous and are derived using a variant of the Hodrick Prescott (1997) filter that allows for additional constraints to be added to the minimization problem to prevent the resulting equilibrium value from converging to the actual observed data at the end of the sample period. These constraints can be used so that the equilibrium value converges toward some user-specified value at the end of the sample period.

Nominal short-term interest rates: 90-day treasury bills or equivalent in percentage points.

Fiscal balance: Annualized quarterly public sector overall fiscal balance in percent of GDP. Source: ONS. 


\section{The Model}

The following provides a complete detailed description of the open-economy model estimated for the U.K. economy and the rest of the world used in this paper. ${ }^{14}$ The model is specified in gap and rate of change terms so that, under inflation targeting, all variables are stationary. For simulation purposes, the equilibrium values for the real interest rate, the real exchange rate, and potential growth rate are assumed to be time invariant. The key behavioral equations are given by the following:

\section{The U.K. economy}

(1) Aggregate Demand (IS function)

$\operatorname{ygap}_{t}=\beta_{1} \cdot \operatorname{ygap}_{t-1}+\beta_{2} \cdot \operatorname{ygap}_{t+1}+\beta_{3} \cdot \operatorname{rrgap}_{t-1}+\beta_{4} \cdot \operatorname{zgap}_{t-1}+\beta_{5} \cdot \operatorname{ygap}_{t}^{*}-\beta_{6} \cdot \mathrm{FBgap}_{t-1}+\varepsilon_{t}^{\text {ygap }}$

(2) Inflation

$\pi_{t}=\delta_{1} \cdot \pi_{t+4}^{4}+\left(1-\delta_{1}\right) \cdot \pi_{t-1}^{4}+\delta_{2} \cdot \operatorname{ygap}_{t-1}+\delta_{3} \cdot \Delta z_{t}+\varepsilon_{t}^{\pi}$,

(3) Real exchange rate

$z_{t}=\varphi \cdot z_{t+1}+(1-\varphi) \cdot z_{t-1}+\left(r r_{t}-r r_{t}^{*}\right) / 4+\varepsilon_{t}^{z} / 4$,

(4) Monetary Policy Reaction Function

$r s_{t}=\alpha_{1} \cdot r s_{t-1}+\left(1-\alpha_{1}\right) \cdot\left(r r_{-} e q_{t}+\pi_{t}^{4}+\alpha_{2} \cdot\left(\pi_{t+4}^{4}-\pi^{T}\right)+\alpha_{3} \cdot y g a p_{t}\right)+\varepsilon_{t}^{r s}$, and

(5) Fiscal Policy Reaction Function

FBgap $_{t}=\theta_{1} \cdot \operatorname{ygap}_{t-1}-\theta_{2} \cdot \operatorname{Dgap}_{t+1}+\varepsilon_{t}^{\text {FBgap }}$.

\section{The rest of the world}

(6) $\operatorname{ygap}_{t}^{*}=\beta_{1}^{*} \cdot \operatorname{ygap}_{t-1}^{*}+\beta_{2}^{*} \cdot \operatorname{ygap}_{t+1}^{*}+\beta_{3}^{*} \cdot \operatorname{rrgap}_{t-1}^{*}+\varepsilon_{t}^{\text {ygap* }}$,

(7) $\pi_{t}^{*}=\delta_{1}^{*} \cdot \pi_{t+4}^{4^{*}}+\left(1-\delta_{1}^{*}\right) \cdot \pi_{t-1}^{4^{*}}+\delta_{2}^{*} \cdot \operatorname{ygap}_{t-1}^{*}+\varepsilon_{t}^{\pi^{*}}$,

(8) $r s_{t}^{*}=\alpha_{1}^{*} \cdot r s_{t-1}^{*}+\left(1-\alpha_{1}^{*}\right) \cdot\left(r r_{-} e q_{t}^{*}+\pi_{t}^{4^{*}}+\alpha_{2}^{*} \cdot\left(\pi_{t+4}^{4^{*}}-\pi^{T^{*}}\right)+\alpha_{3}^{*} \cdot y g a p_{t}\right)+\varepsilon_{t}^{r s^{*}}$,

where ygap is the output gap, $r r$ is the domestic real interest rate, $r r \_e q$ is it equilibrium real interest rate, $r s$ is the annualized short-term policy rate, $z$ is the log of the real exchange rate index (an increase implies a depreciation), $\pi$ is the quarterly annualized rate of CPI inflation, $\pi^{4}$ is a four-quarter moving average of quarterly annualized CPI inflation, $\pi^{T}$ is the target rate of inflation, $F B$ is the fiscal balance, $D$ is the government debt, and Dgap is the deviation from the government's debt target $D^{*}$.

\footnotetext{
${ }^{14}$ See Berg et al. (2006) for an extensive description of the model with an application to Canada.
} 
The model is specified in gap terms, defined as the deviation from the equilibrium value. In addition, $\Delta$ is the first difference operator, * denotes foreign variables, $\varepsilon$ is the stochastic error process. Parameters are given by the $\beta_{s}, \delta_{s}, \varphi$, and $\alpha_{s}$.

The fiscal rule is designed to allow for the effects of automatic stabilizers and at the same time achieve a stable public debt target. Fiscal policy responds to period t-1's output gap by reducing (adding) demand stimulus when there is positive (negative) output gap in the economy, but at the same time, it has a forward-looking component aiming at achieving the government's target for public debt. The presence of the automatic stabilizer ensures that the fiscal balance contributes to reducing the output gap in the economy in equation (1). Similar rules can be found in many industrialized countries where fiscal policy is mainly governed by automatic stabilizers while meeting targets for the level of government debt. ${ }^{15}$ For this exercise, debt is defined as the cumulative fiscal balance, and the debt target is set equal to zero, which implies the equilibrium fiscal balance is zero and there is no debt accumulation overtime. This can be thought of as normalization around a nonzero, but constant, ratio of public debt to GDP.

\section{Stochastic processes}

(9) $\varepsilon_{t}^{\text {ygap }}=\rho^{\text {ygap }} \cdot \varepsilon_{t-1}^{\text {ygap }}+\xi_{t}^{\text {ygap }}$,

(10) $\varepsilon_{t}^{\text {ygap* }}=\rho^{\text {ygap } *} \cdot \varepsilon_{t-1}^{\text {ygap* }}+\xi_{t}^{\text {ygap* }}$,

(11) $\varepsilon_{t}^{\pi}=\rho^{\pi} \cdot \varepsilon_{t-1}^{\pi}+\xi_{t}^{\pi}$,

(12) $\varepsilon_{t}^{\pi^{*}}=\rho^{\pi^{*}} \cdot \varepsilon_{t-1}^{\pi^{*}}+\xi_{t}^{\pi^{*}}$,

(13) $\varepsilon_{t}^{r s}=\rho^{r s} \cdot \varepsilon_{t-1}^{r s}+\xi_{t}^{r s}$,

(14) $\varepsilon_{t}^{r s^{*}}=\rho^{r s^{*}} \cdot \varepsilon_{t-1}^{r s^{*}}+\xi_{t}^{r s^{*}}$,

\section{Identities}

$\pi_{t}^{4}=\left(\pi_{t}+\pi_{t-1}+\pi_{t-2}+\pi_{t-3}\right) / 4$

$\pi_{t}^{4^{*}}=\left(\pi_{t}^{*}+\pi_{t-1}^{*}+\pi_{t-2}^{*}+\pi_{t-3}^{*}\right) / 4$,

$$
r r_{t}=r s_{t}-\pi_{t+1}
$$

\footnotetext{
${ }^{15}$ Few examples would be the fiscal framework in New Zealand, Canada, and Australia.
} 
(18) $r r_{t}^{*}=r s_{t}^{*}-\pi_{t+1}^{*}$,

(19) $r r g a p_{t}=r r_{t}-r r_{-} e q_{t}$,

(20) $r r g a p_{t}^{*}=r r_{t}^{*}-r r_{-} e q_{t}^{*}$,

(21) zgap $_{t}=z_{t}-z_{-} e q_{t}$.

\section{Estimation and simulation}

The models’ parameter values are estimated from the data using a Bayesian technique. The estimation has been done allowing for measurement error in the observable variables. The priors and the resulting estimates for the United Kingdom and the rest of the world are presented in Tables 1 and 2. All simulations were conducted using a custom-built TROLL programs. 
Table 1: United Kingdom: Model Parameter Estimation Results 1/ Sample period 1992Q1 to 2006Q4

\begin{tabular}{|c|c|c|c|}
\hline Parameter & $\begin{array}{l}\text { Prior } \\
\text { Mean }\end{array}$ & Distribution & $\begin{array}{c}\text { Posterior } \\
\text { Mean }\end{array}$ \\
\hline \multicolumn{4}{|l|}{ United Kingdom } \\
\hline$\beta_{1}$ (coefficient on own lag in ygap) & 0.85 & gamma & 0.743 \\
\hline$\beta_{2}$ (coefficient on own lead in ygap) & 0.10 & beta & 0.093 \\
\hline$\beta_{3}$ (coefficient on rgap in ygap) & 0.10 & gamma & 0.104 \\
\hline$\beta_{4}$ (coefficient on zgap in ygap) & 0.05 & beta & 0.037 \\
\hline$\beta_{5}$ (coefficient on ygap* in ygap) & 0.15 & beta & 0.200 \\
\hline$\beta_{6}$ (coefficient on fbgap in ygap) & 0.17 & beta & 0.165 \\
\hline$\delta_{1}$ (coefficient on own lead in $\pi$ ) & 0.20 & beta & 0.192 \\
\hline$\delta_{2}$ (coefficient on ygap in $\pi$ ) & 0.30 & gamma & 0.272 \\
\hline$\delta_{3}$ (coefficient on $\Delta$ zin $\pi$ ) & 0.10 & gamma & 0.087 \\
\hline$\theta_{1}$ (coefficient on ygap in FBgap) & 0.18 & beta & 0.182 \\
\hline$\theta_{2}$ (coefficient on Dgap lead in FBgap) & 0.10 & beta & 0.104 \\
\hline$\varphi$ (coefficient on own lead in z) & 0.50 & beta & 0.335 \\
\hline$\alpha_{1}$ (coefficient on own lag in rs) & 0.50 & beta & 0.537 \\
\hline$\alpha_{2}$ (coefficient on inflation gap in rs) & 2.00 & beta & 1.849 \\
\hline$\alpha_{3}$ (coefficient on ygap in $r s$ ) & 0.50 & beta & 0.520 \\
\hline \multicolumn{4}{|l|}{ Rest of the World } \\
\hline$\beta_{1}^{\star}($ coefficient on own lag in ygap*) & 0.85 & gamma & 0.762 \\
\hline$\beta_{2}^{*}$ (coefficient on own lead in ygap*) & 0.10 & beta & 0.102 \\
\hline$\beta_{3}^{*}($ coefficient on rrgap* in ygap*) & 0.10 & gamma & 0.111 \\
\hline$\delta_{1}^{*}$ (coefficient on own lead in $\pi^{\star}$ ) & 0.20 & beta & 0.185 \\
\hline$\delta_{2}^{*}$ (coefficient on ygap* in $\pi^{\star}$ ) & 0.30 & gamma & 0.230 \\
\hline$\alpha_{1}^{*}($ coefficient on own lag in rs*) & 0.50 & beta & 0.558 \\
\hline$a_{2}^{*}($ coefficient on inflation gap in rs*) & 2.00 & gamma & 1.980 \\
\hline$\alpha_{3}^{*}\left(\right.$ coefficient on ygap* in $\left.r^{*}\right)$ & 0.30 & beta & 0.230 \\
\hline
\end{tabular}

Sources: Staff estimates. 
Table 2: United Kingdom: Estimation Results for the Error Processes and Measurement Errors Sample period 1992Q1 to 2006Q4

\begin{tabular}{|c|c|c|c|}
\hline Parameter & $\begin{array}{l}\text { Prior } \\
\text { Mean } \\
\end{array}$ & Distribution & $\begin{array}{c}\text { Posterior } \\
\text { Mean }\end{array}$ \\
\hline \multicolumn{4}{|l|}{ United Kingdom } \\
\hline$\rho^{\text {ygap }}$ & 0.75 & beta & 0.810 \\
\hline std. dev. $\xi^{y g a p}$ & 0.25 & inverse gamma & 0.175 \\
\hline std. dev. mes. er. ygap & 0.20 & inverse gamma & 0.121 \\
\hline$\rho^{\pi}$ & 0.50 & beta & 0.491 \\
\hline std. dev. $\xi^{\pi}$ & 0.25 & inverse gamma & 0.304 \\
\hline std. dev. mes. er. " & 0.20 & inverse gamma & 2.137 \\
\hline$\rho^{r s}$ & 0.75 & beta & 0.765 \\
\hline std. dev. $\xi^{\mathrm{rs}}$ & 0.25 & inverse gamma & 0.157 \\
\hline std. dev. mes. er. ${ }^{\text {rs }}$ & 0.20 & inverse gamma & 0.117 \\
\hline std. dev. $\varepsilon^{z}$ & 4.00 & inverse gamma & 5.608 \\
\hline std. dev. $\varepsilon^{\text {FBgap }}$ & 0.25 & inverse gamma & 1.248 \\
\hline std. dev. $\varepsilon^{\mathrm{D}}$ & 0.25 & inverse gamma & 0.051 \\
\hline \multicolumn{4}{|l|}{ Rest of the World } \\
\hline$\rho^{\operatorname{ygap} p^{*}}$ & 0.75 & beta & 0.751 \\
\hline std. dev. $\xi^{y g a p^{\star}}$ & 0.25 & inverse gamma & 0.178 \\
\hline std. dev. mes. er. ygap & 0.20 & inverse gamma & 0.149 \\
\hline$\rho^{\pi^{*}}$ & 0.50 & beta & 0.530 \\
\hline std. dev. $\xi^{\pi^{*}}$ & 0.25 & inverse gamma & 0.150 \\
\hline std. dev. mes. er. ${ }^{\pi^{*}}$ & 0.20 & inverse gamma & 1.046 \\
\hline$\rho^{r s^{*}}$ & 0.75 & beta & 0.823 \\
\hline std. dev. $\xi^{r \mathrm{~s}^{*}}$ & 0.25 & inverse gamma & 0.154 \\
\hline std. dev. mes. er. ${ }^{r{ }^{*}}$ & 0.20 & inverse gamma & 0.152 \\
\hline
\end{tabular}

Sources: Staff estimates. 